\title{
Methodology for the rehabilitation of ancient gypsum plasterwork
}

Received (in revised form): 23rd June, 2007

\section{Hélder Cotrim}

is an architect and has an MSc in Construction from IST - Technical University of Lisbon. His research is concerned with the inspection, diagnosis, and rehabilitation of ancient gypsum plasters.

\section{Maria do Rosário Veiga}

is a civil engineer from IST - Technical University of Lisbon and received her doctoral degree in civil engineering from Faculdade de Engenharia da Universidade of Porto (FEUP), and is a senior researcher in the National Laboratory of Civil Engineering (LNEC). She is the Portuguese expert in the European Normalization Committee for rendering and plastering mortars and in the EOTA Working Group for preparation of an Approval Guide for External Thermal insulation Composite Systems. She is also a member of the RILEM Committee for Repair Mortars for Historic Masonry (RHM). She collaborates in several Masters Courses in Civil Engineering and Architecture of Universities of Lisbon, Coimbra, and Porto. Her research work is related to the performance of wall-covering systems, the durability and rehabilitation of wall coverings, and the conservation of historic mortars.

\section{Jorge de Brito}

graduated in Civil Engineering and received his Masters and Doctoral degrees at IST - Technical University of Lisbon, Portugal, where he is currently an associate professor. He is a member of IABSE, FIB, CIB, and IABMAS, as well as of several reputed national engineering societies and is a member of the following working groups: CIB W80/RILEM 100-TSL - Service Life Prediction of Building Materials and Components; CIB W86 - Building Pathology; CIB W115 - Construction Materials Stewardship; and several national committees under CEN. His research work deals with deterioration, rehabilitation, and management of concrete structures. He has co-authored the 'Handbook of Concrete Bridge Management', published by ASCE Press in 2004.

Correspondence: Jorge de Brito, Department of Civil Engineering and Architecture, Section of Construction, IST - Technical University of Lisbon, Av. Rovisco Pais, 1049-001 Lisbon, Portugal; Tel: (351) 21 8419709; Fax: (351) 21 8497650; E-mail: jb@civil.ist.utl.pt

\begin{abstract}
The rehabilitation of ancient gypsum plasterwork demands a systematic procedure in order to obtain a complete knowledge of the action's context, to identify the main anomalies, and to select the materials and techniques needed for their performance. The characteristics of construction elements demand also that actions are subjected to a strict planning, using a procedure where observation plays a fundamental role in identifying and inspecting the various components of the plastered element. This paper describes a methodology proposed for the rehabilitation of ancient gypsum plasterwork comprising the appraisal and inspection of the building's conservation status, the analysis of the data collected, the preparation of restoration project, and the decisions made on site. Journal of Building Appraisal (2007) 3, 195-212. doi:10.1057/palgrave.jba.2950075
\end{abstract}

\section{Keywords:}

gypsum plasterwork, rehabilitation, appraisal, inspection, methodology, restoration

\section{INTRODUCTION}

There are many international references (manuals and scientific works) concerning plasterwork and its rehabilitation (Leeke, 1985a, 1985b; Leeke, 1987; Poore, 1988; Alessandrini et al., 1989; Shivers, 1989; Hodgson, 1901; Millar, 1998; Vadstrup, 2001; Isik, 2001; Bankart, 2002; Eckel, 2005; Callieri et al., 2006; Sawyer, 2007). This has not been, however, the case in Portugal where there is a significant tradition of gypsum 
plasterwork and where the investigation of the artistic, social, and technical history of gypsum plasters is lacking with only a few examples in the literature. Two studies by Flórido de Vasconcelos $(1991,1997)$, a monograph about a village called Afife, near Viana do Castelo (Meira, 1999), and scattered references in regional publications made by people with ties to that village, from where many gypsum plasterers came from, as well as the technically oriented research of Ribeiro (2000), and Ribeiro et al. (2007) are all that exist. Thus the rehabilitation of ancient gypsum plasterwork in Portugal has suffered because of the lack of local references.

It is important that all participants in a rehabilitation work of this nature understand that its success depends on a strict methodology, and without that the probability of a bad result is very high. In this paper, the rehabilitation stages are analysed sequentially in terms of research and of the process itself. Lack of compliance with these stages is, however, not the only factor that contributes to rehabilitation failure as it is common to go forward with works of this nature without a complete knowledge of the causes of damage that led to a need for the remedial works. From this faulty procedure, unfruitful actions can arise due to ignorance of the works context and reoccurrence of existing and/or development of new defects.

Furthermore, a detailed knowledge of the traditional techniques used, history of the buildings, and the characteristics (composition and compatibility with original materials) of the materials used during rehabilitation is essential.

All participants need to be conscious that rehabilitation work differs from new construction since, as the works proceed, a continuous analysis of the buildings elements' characteristics is needed. It is thus clear that the various tasks must follow a strict experimental approach and that at each stage, changes from the previously established intervention plan may be needed.

Some of the subjects related to the intervention stages within a rehabilitation work can be found in papers and technical, specialised publications, as follows:

- Ancient gypsum plasterwork by Leeke (1985a, 1985b, 1987), Ashurst and Ashurst (1988), Poore (1988), Shivers (1989), Gárate Rojas (1999), and Vadstrup (2001).

- Historical buildings by Alessandrini et al. (1989), Isik (2001), Feilden (2003), and Callieri et al. (2006).

- A paper on the rehabilitation of the Bishop's Palace of Porto by Silva (2001).

Some other more general references also contain pertinent data, namely:

- Gypsum plasterwork: Manuals by Hodgson (1901), Millar (1998), Bankart (2002), Eckel (2005), and Sawyer (2007).

- Planning of interventions by Mateus (2002).

- External ornaments in façades by Vadstrup (2001).

- Rehabilitation of timber structures by Faria (2002).

The 2003 document on rehabilitation of the Freixo Palace in Porto (Figure 1) is also important in the context of the present study (Cotrim et al., 2006).

To summarise, the intervention method for the rehabilitation of ancient gypsum plasterwork described in the present paper is based on four fundamental vectors (Cotrim, 2004) as follows:

(1) appraisal and inspection of the building's conservation status;

(2) analysis of the data collected; 


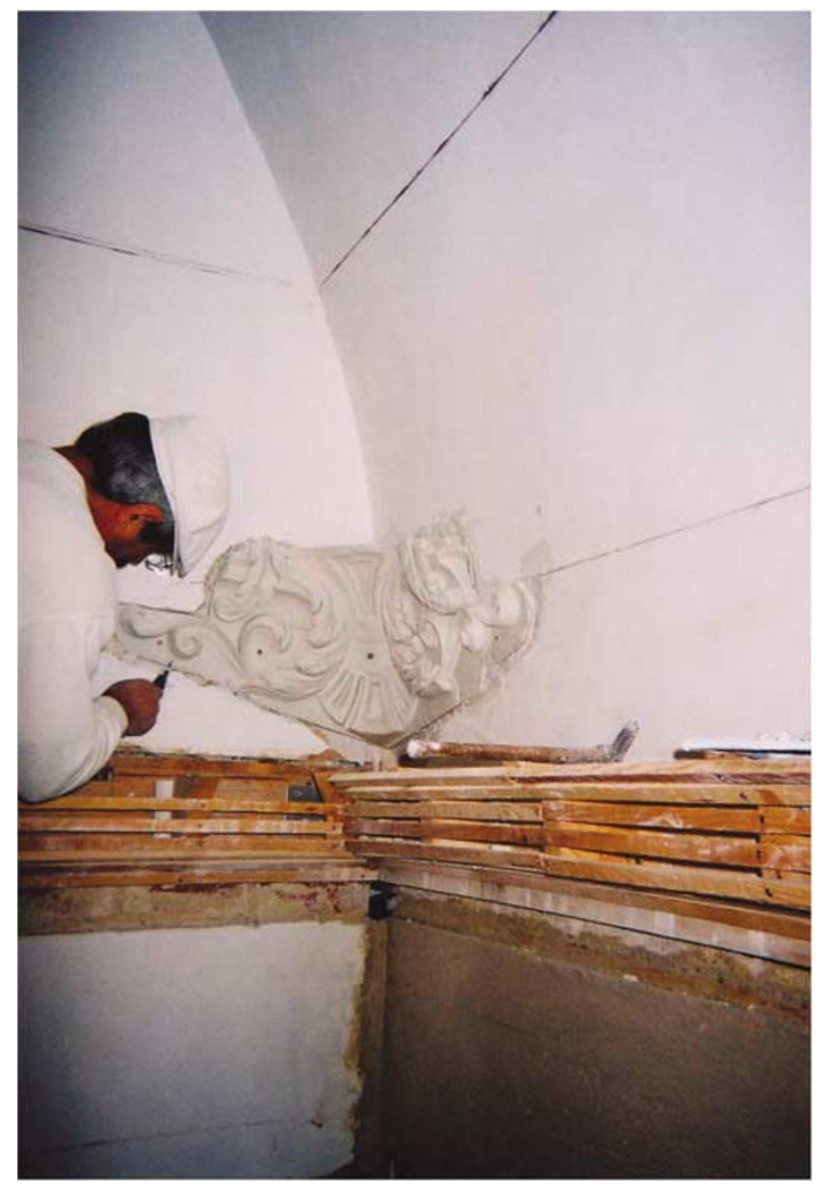

Figure I: Reinstatement of the decoration in gaps of great dimension in a ceiling (Freixo Palace in Porto) (Cotrim et al., 2006)

(3) preparation of the restoration project;

(4) decisions made on site.

\section{APPRAISAL AND INSPECTION OF THE BUILDING'S CONSERVATION STATUS}

The first stage of the rehabilitation process of a historical building is a detailed examination of the structure and the mechanisms responsible for its degradation. In this context, two lines of action are referred: appraisal and inspection. Although there is no clear separation between these concepts, it is understood that they have different procedures and objectives.

Appraisal is associated to research of a morphological/constructive nature usually by direct observation, and inspection is related to actions capable of characterising the degradation of the elements and their stability as a function of the anomalies and their degree of incidence, usually by quantification and comparison of objective evaluation parameters.

In buildings where observation is neglected, during rehabilitation works commonly, undetected problems arise and they lead to changes in design, consequent increase in 
costs and increase in duration of the work. According to Cramer (1986), only exhaustive site knowledge allows for an activity without surprises. The potential of appraisal and inspection is that they are the first contact of the designers with the historical buildings and are, therefore, an excellent opportunity to obtain an integral knowledge of them.

The actions to be developed must be focussed on the areas most important for the general analysis of the building allowing its constructive characterisation as follows:

- historical focus, with attention to interventions after the initial construction;

- morphological and compositive focus, on construction elements and decorations, respectively;

- structural and constructive focus.

\section{Appraisal}

Appraisal of a building must not be limited to a general description. It must give rise to a document of an analytical nature with all the data needed to completely know the object under analysis. Besides registering construction techniques and anomalies, the history of the most important elements, building transformations, construction materials etc must be noted. A detailed appraisal contributes to effective cost control since it allows adoption of solutions that minimise unexpected problems which are so very often responsible for unexpected increase in costs, resulting from delays, changes in solutions, or interruptions of the works.

The historical appraisal consists of the collection of data relating to the evolution of the building, namely extensions, refurbishments, accidents, and changes of landlord, aiming at identifying every intervention since initial construction. These data may be needed to identify differential settlements of the building or to detect traces of previous interventions hidden by subsequent ones.

A morphological and composite appraisal is necessary to determine the design of the plastered elements for symmetry, repetition, and shape (Figure 2) among others, and is essential for the process of reintegrating missing patches. It is performed using current easy-to-use appraisal methods, such as photography, drawings at conventional scales and hand-drawn sketches indicating dimensions, and the register of formal, stylistic, and chromatic characteristics (Gleeson, 2002). Nevertheless, whenever deemed necessary, more sophisticated technical means must be used, for example thermography.

In terms of morphology, the following items must be registered:

(a) the geometry of the elements;

(b) missing patches that can be replaced by copying other elements;

(c) missing patches in areas where reproduction is difficult or impossible;

(d) the configuration of the plasters' background supporting system.

Concerning the materials and characteristics of the gypsum plasters, one must register:

(a) the composition (through chemical and mineralogical analyses), namely the nature and possible soluble salt content;

(b) the petrography (through texture and structure analyses);

(c) the number and thickness of layers; 

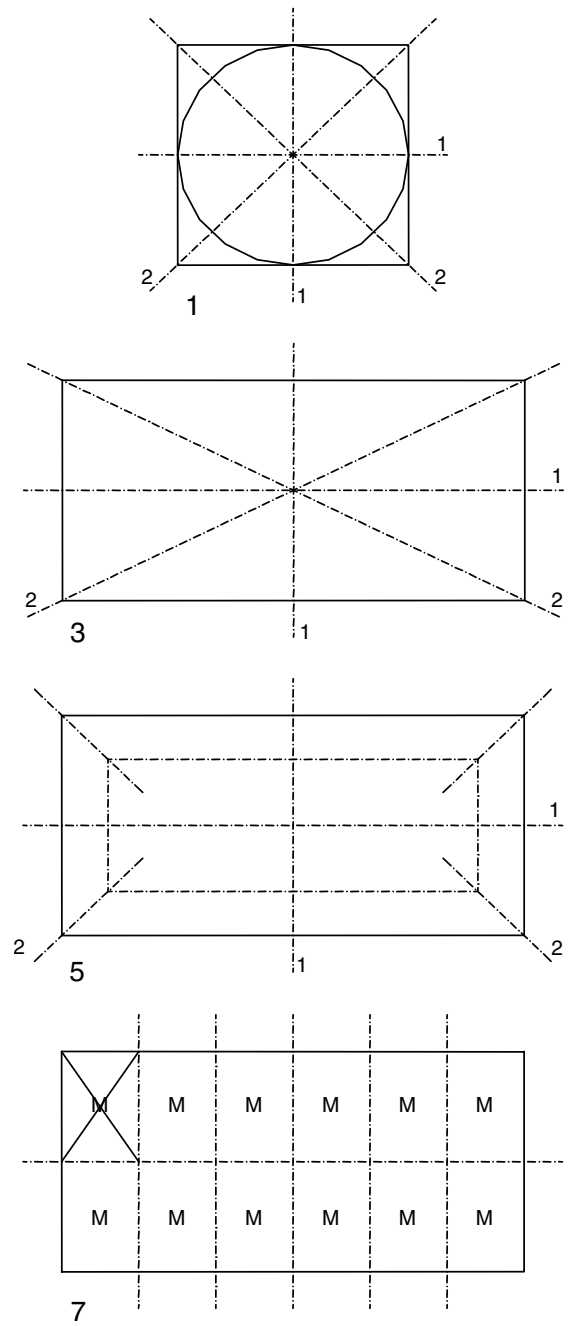

1/2 Symmetry plan M Module

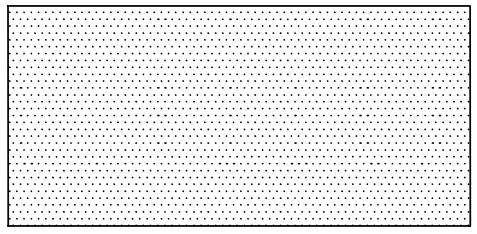

2
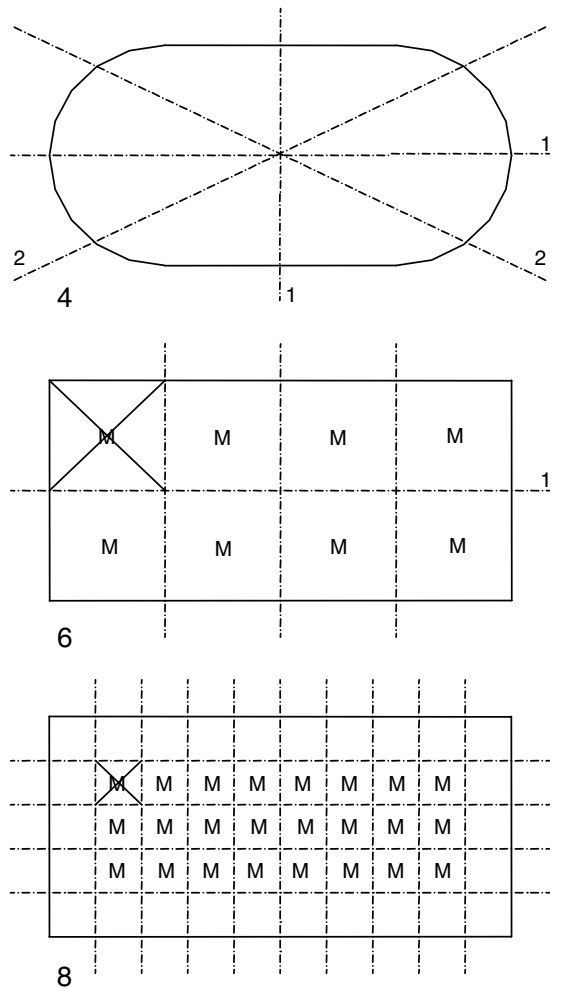

Figure 2: Composition diagrams of gypsum-plastered roofs. Symmetric compositions: diagrams I, 3, 4, and 5. Modular compositions: diagrams 6, 7, and 8. Nonsymmetric compositions without modules repetition: diagram 2

(d) the characterisation of the existing paints, namely whether they are originals or copies, their conservation status, nature, colours, and pigments used.

In terms of anomalies, the following items should be registered:

(a) damp areas;

(b) the effects of dampness;

(c) the existence of efflorescence and cryptoflorescence situations, and the configuration of the respective salts;

(d) decayed or powdery areas;

(e) cracks (dimensions, location, and geometry) (eg Figure 3);

(f) patches with loss of adhesion; 


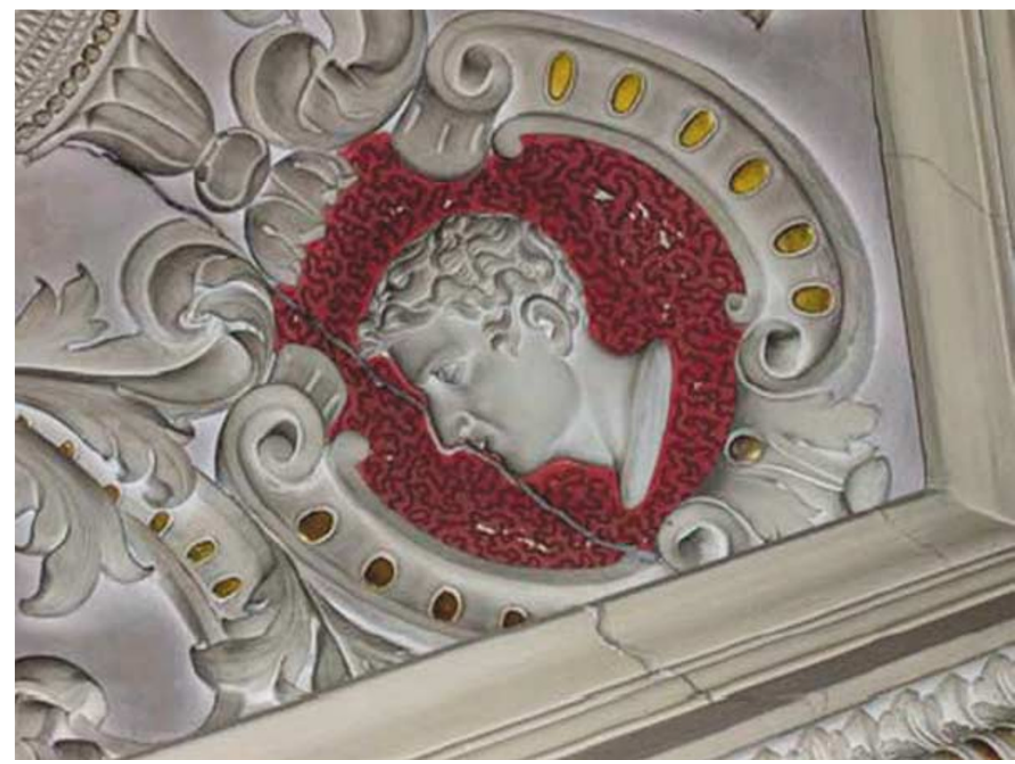

Figure 3: Cracking in ornaments (Marquis of Tomar Palace in Lisbon)

(g) missing patches;

(h) stained areas;

(i) stains of a biological or chemical nature;

(j) stains caused by iron elements.

Finally, the effects of random and accidental causes must be registered, namely as follows:

(a) inadequate interventions due to the use of incompatible materials or coarse corrections;

(b) incorrect repainting;

(c) occasional water entrances (eg Figure 4);

(d) damage caused by fire or vandalism.

The results of the appraisal and its main conclusions must be compiled in a document that is the starting point for further actions, namely the inspection and the preparation of the restoration project. Data are presented in writing, drawings, and photographs. According to Cramer (1986), drawn registers are one of the most effective means of scientific approach to a building, independent of the type of research, historical or constructive, or simply to implement rehabilitation works.

\section{Inspection}

It is essential to proceed with inspection actions, determined to measure the state of degradation of the construction elements and the degree of incidence of anomalies. In an inspection, these parameters allow an objective evaluation and quantification by comparison with standard situations.

To adequately perform the inspection tasks, one needs to establish a set of objectives, framed by the motives that determined the analysis of the general or specific conditions of 


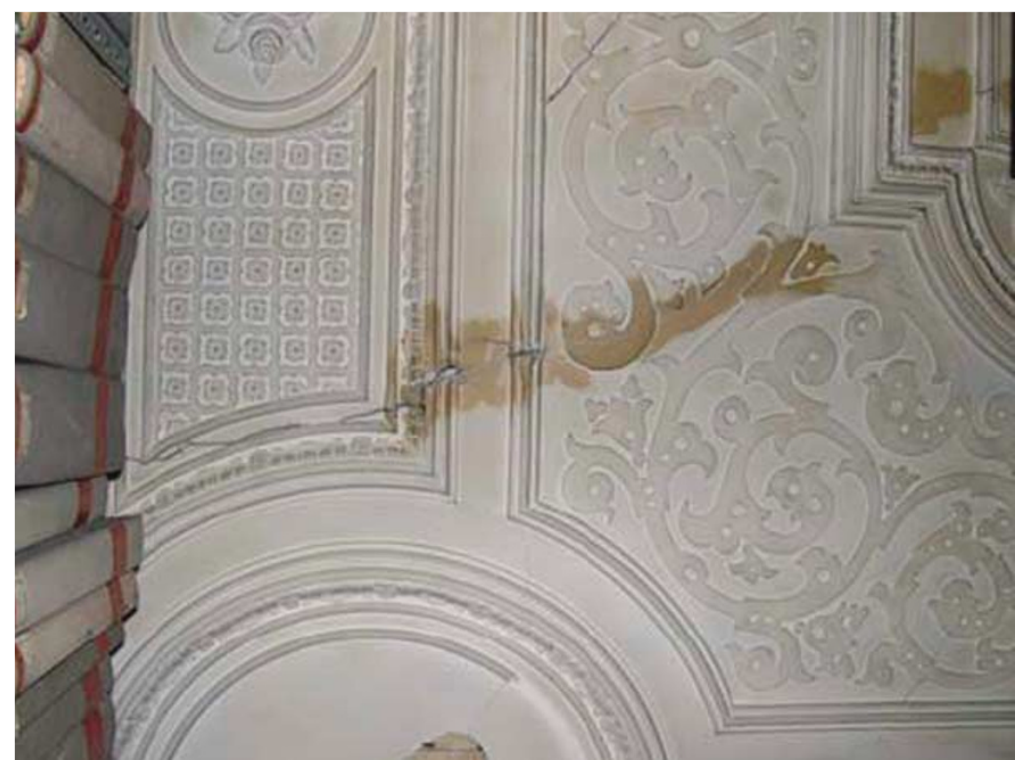

Figure 4: Stains caused by water entrance (Marquis of Tomar Palace in Lisbon)

the gypsum plasterwork (Henriques, 2001), namely with one or more of the following intentions:

- to rehabilitate partially or totally the gypsum plasterwork;

- to prepare a maintenance plan;

- to evaluate the extension of spontaneous damage;

- to budget various works;

- to identify the construction conditions and materials;

- to draw at a proper scale the ornaments or the constructive characteristics;

- to register the situation in photos.

According to Feilden (2003), the success of rehabilitation results mostly from the correct selection of the techniques adequate to a certain research and from the capacity of interpretation of the data, in order to guarantee the maximum reliability and capacity to make good decision during the rehabilitation process.

\section{Gypsum plasterwork's specific aspects}

The evaluation of the condition or state of a gypsum plaster cannot be obtained solely from the covering and its intrinsic properties since it hides and coats the materials that compose the walls and roofs and it can, therefore, hinder a complete perception of the damage in the background and of its extent. Nevertheless, since gypsum plaster is a brittle material with a limited deformation capacity, it can also expressively testify some anomalies, namely: structural deformations of the building, by cracking; water entrances through the envelope, by stains and swelling; and biological growth, also by stains, in all of these cases without revealing the origin of the damage.

To perform an objective inspection, it is paramount to examine the fraction of hidden damage of ancient buildings that gypsum plasterwork helps to reveal. There are situations in which this inspection demands the use of complex techniques, resorting to costly and 
difficult-to-use equipments, such as the ones that use nonconventional energy sources (ultra-sound, ionising radiation and magnetic fields).

\section{Stages of an inspection}

Inspection starts with initial observations and then the inspection plan is prepared, in which the procedures for executing the various tasks, as well as the methods and techniques to be used, are established. Finally, an inspection report is prepared, described in the chapter dedicated to the analysis of the data collected.

Initial observations. Through visual observation, an initial approach to the problems is undertaken, clarifying uncertainties caused by the analysis of existing documents. This allows a preliminary diagnosis of the possible causes of the anomalies and, therefore, guidelines concerning inspection and identification of aspects that need previous planning, for example, access to high or hidden locations and those that might collapse, and other less important aspects with some potential to hinder the development of the inspection.

Inspection plan. Existing data on the building allow the preparation of the inspection plan, which establishes the methodology that maximises the efficiency of its results and avoids having to return to the location for confirmation or collection of incomplete or missing data. The inspection plan is the preliminary document where all the conditioning factors concerning the inspection operations are registered, namely restrictions imposed by the building's use, necessary resources and data to be collected, as well as an estimate of the inspection costs.

Inspection of the conditions. In the case of gypsum plasterwork, inspections may vary between a mere observation and the use of sophisticated equipment of electronic analysis. From the inspection's onset, it is, however, essential to be able to interpret the evidence exposed on the plaster, namely stains, fungus/bacteria and discoloration, and on the backgrounds, such as dust vestiges resulting from xylophagous, smell of decayed timber, or the presence of fungus. Every human sense must, therefore, be used in searching for clues (Feilden, 2003).

By visual observation, the first level of inspection, evidence is observed: visible defects, revealing hidden anomalies in most situations, for example, damage to background structure; the relationship between the lathing and the pavements and roofs' coating; timber condition; the state of fastenings of the ornaments; configuration, disposition and angle of inclination of cracking; and evidence of poorly performed interventions, both from initial construction and rehabilitation. Every detail showing a good performance must be registered in order to contribute to the definition of the future rehabilitation (Feilden, 2003).

Finally, concerning polychromes, inspection is relevant from an artistic, historical, and archaeological point of view. One has to carry out the studies necessary for their rehabilitation, which involves complex actions of cleaning and restoration. In the case of ancient paints covered by recent painting layers, rehabilitation demands the almost surgical removal of these layers in limited areas, called windows, of an adequate dimension to visualise the polychrome or the decorative compositions (Figure 5).

The second level of inspection consists of a physical examination with limited impact, that is, actions that leave no trace or adverse effect on the surfaces or ornaments. This examination is a complement to visual inspection, such as tapping the surface helps in determining the adherence of parcels apparently detached from the background or 


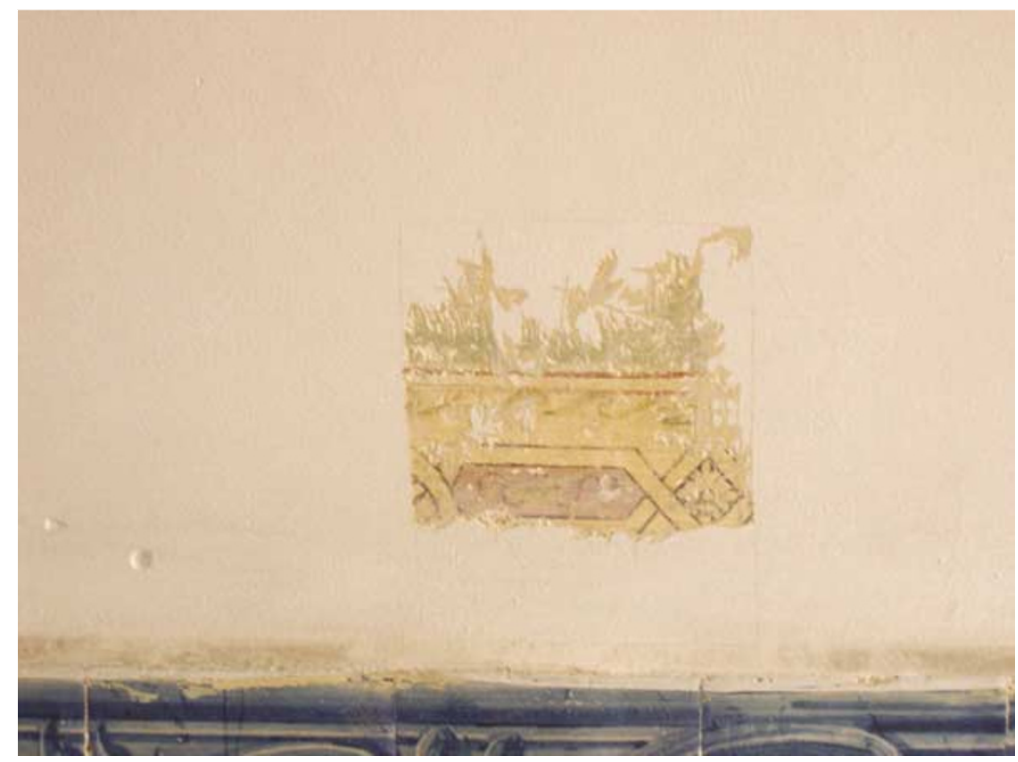

Figure 5: Removal of contemporary paintings to inspect hidden polychromes (Marquis of Pombal Palace in Lisbon)

delaminated. The use of manual inspection also allows the determination of the consistency of ornaments or of eventual desegregation of pigmentation in polychromatic decorations.

At a third level, nondestructive tests can be used since historical buildings present less than 10 per cent of their elements in conditions to be analysed solely by direct observation (Feilden, 2003). As a matter of fact, most of the visible damage in gypsum plasters results from causes within the remaining 90 per cent elements, that is, those hidden underneath the soil, underneath the plaster or hidden by other coverings or decorations. It is thus necessary to probe hidden locations and those with difficult access, part of which are observed, and analysed only as the works proceed.

According to Feilden (2003), it is within this scope that nondestructive tests must be selected, in order not to cause any changes or new damage. It must be stressed although that some of these inspection techniques are costly and that some are hard to apply and to interpret, even though others are used almost routinely in the field of specialised architectural heritage preservation. Therefore, their adoption is thought to be advantageous for elements with a high heritage value that cannot be damaged at all, not even within the scope of rehabilitation.

The determination of damage in hidden areas is made by resorting to measuring devices, to identify anomalies whose elimination requires physical intervention, for example, stabilisation of backgrounds. These are complex inspections that may involve non-negligible costs, such as radiography, thermography and infrared photography, ultra-sound, magnetometer, and endoscopic measurements. Some of these techniques have some drawbacks, such as the need for the equipment to be handled by professionals with much experience, and the complex nature of interpretation of the results (Binda et al., 2000; Santos et al., 2003; Magalhães et al., 2005).

These nondestructive techniques are tools used to answer specific and local issues and are no substitute for experience, achieved through observation and understanding of the results obtained in inspections performed in many ancient buildings. 
Finally, interventions with a high physical impact can also be used whenever necessary to remove small samples of construction elements for laboratory analysis, for example, cores to verify the constructive conditions and status of the walls/roofs. These operations should be performed in the least visible possible locations and to an extent strictly necessary for the analysis. In situations where great damage is detected, it may be necessary to remove the deteriorated decoration for later copying or repositioning.

Within the scope of inspection, it is also significant to refer to the monitoring of anomalies. The importance of this procedure is due to the multiplicity of actions that influence the behaviour and degradation of construction elements in an historical building throughout time. Therefore, monitoring its ageing in an inspection is extremely important to effectively control the evolution of the anomalies. Within this context, the existence of previous reports allows evaluation of the progress of the anomalies and improves decision making (Feilden, 2003). The progress of certain kinds of damage can, however, only be measured through permanent observation during a fixed period. This involves an absolute or relative measurement that provides reliable data and is capable of registering the progress of dimensional variations. Permanent monitoring of the evolution of the anomalies allows the more effective understanding of the causes of decay and the establishment of more adequate forms of interventions.

Data register. Similar to data collected during appraisal, inspection data must be registered in documents that can be drawn (plans, elevations, cross-sections, and detailing sketches) and written (a description of the development of the inspection and others). They are paramount to the precise quantification of damage and the intervention deemed necessary. After collecting and registering these data, the next step is their evaluation in order to establish intervention strategies and to estimate costs involved in the rehabilitation.

\section{ANALYSIS OF THE DATA COLLECTED}

Feilden emphasises inspection as an essential action to define future rehabilitation actions. In the case of gypsum plasterwork, anomalies testify the damage undergone by the building, at the level of the envelope and structural conditions. It matters, therefore, to perform a detailed evaluation of the data collected in order to establish the rehabilitation principles of other elements.

This evaluation allows establishment of the general framework and criteria leading to the preparation of the intervention plan, contributing to defining the objectives, the stages, and the profitability of the available financial resources. It can also be a strong enough motive to examine the usefulness of existing methods and to call attention to new techniques (Silva, 2001).

Although the main objective of rehabilitating gypsum plasterwork is the reinstatement of their stability and aesthetic features, conclusions drawn from the inspection results must also allow eliminating existing anomalies and prevent the occurrence of new ones. This is done through the adoption of procedures and materials about which there are no doubts concerning compatibility with pre-existing conditions, namely structural, chemical, material-related, or aesthetic.

Finally, evaluation gives all people involved in the process (promoters, designers, contractors) the proper information for correct actions aimed at maximum efficacy in different areas. 


\section{Inspection results}

Data obtained during inspection are the starting point to back decision making and to establish the global logic of intervention, concerning the need and level of priority of the various actions.

Inspection is a methodological mechanism. So, a document containing the compilation and analysis of data must be prepared, called the inspection report. It must be complemented with action proposals or recommendations of any other nature and, according to Feilden (2003), must be organised as follows:

(a) Initial report, consisting a register and description of all anomalies, as well as analysis of the building's constructive conditions; it is based on visual inspection.

(b) Maintenance plan, where the intervention priorities are established, in terms of the degradation risk of certain elements.

(c) Historical research, which contains the analysis of the building's historical characteristics; it resorts to a photographic register and bibliographic research.

(d) Register of the general status of the building: soil conditions, dampness levels etc.

(e) Structural analysis, which describes the structural conditions of the building and registers other complementary studies made for the same effect.

(f) Composition of materials used on plasterwork (namely plaster and paint composition).

(g) Estimate of the costs of the intervention proposals, destined to the entity responsible for the building management, to be properly evaluated in financial terms.

As an example of the potential variety of the solutions, a study of Henriques (2001) on dampness of walls is mentioned. The author classifies various intervention strategies, which range from those of a provisional nature to interventions in depth, with incidence on the strengthening of functional characteristics of the envelope, as presented below:

(a) Elimination of the anomalies, a provisional action with no overall measures.

(b) Replacement of the elements/materials affected, when rehabilitation is difficult/not viable, using compatible materials (Veiga et al., 2001).

(c) Protection against aggressive elements (eg Church of Cowdray House rehabilitation works (Ashurst and Ashurst, 1988)).

(d) Elimination of the causes of the anomalies, performed before any operation on the plasterwork.

(e) Strengthening of the functional characteristics of the construction elements, possibly involving interventions in other elements, besides the gypsum plasters and their background.

\section{Maintenance plan}

The maintenance plan consists of a set of recommendations destined to rank the action priorities, from the works to be executed immediately to the identification of the situations with potential to cause new damage and, therefore, to be watched closely. For the particular case of gypsum plasterwork, the maintenance plan must not be limited to the actions aiming at stopping active damage, but also include those that stop the development of short-term situations that compromise maintenance of the plasterwork. 


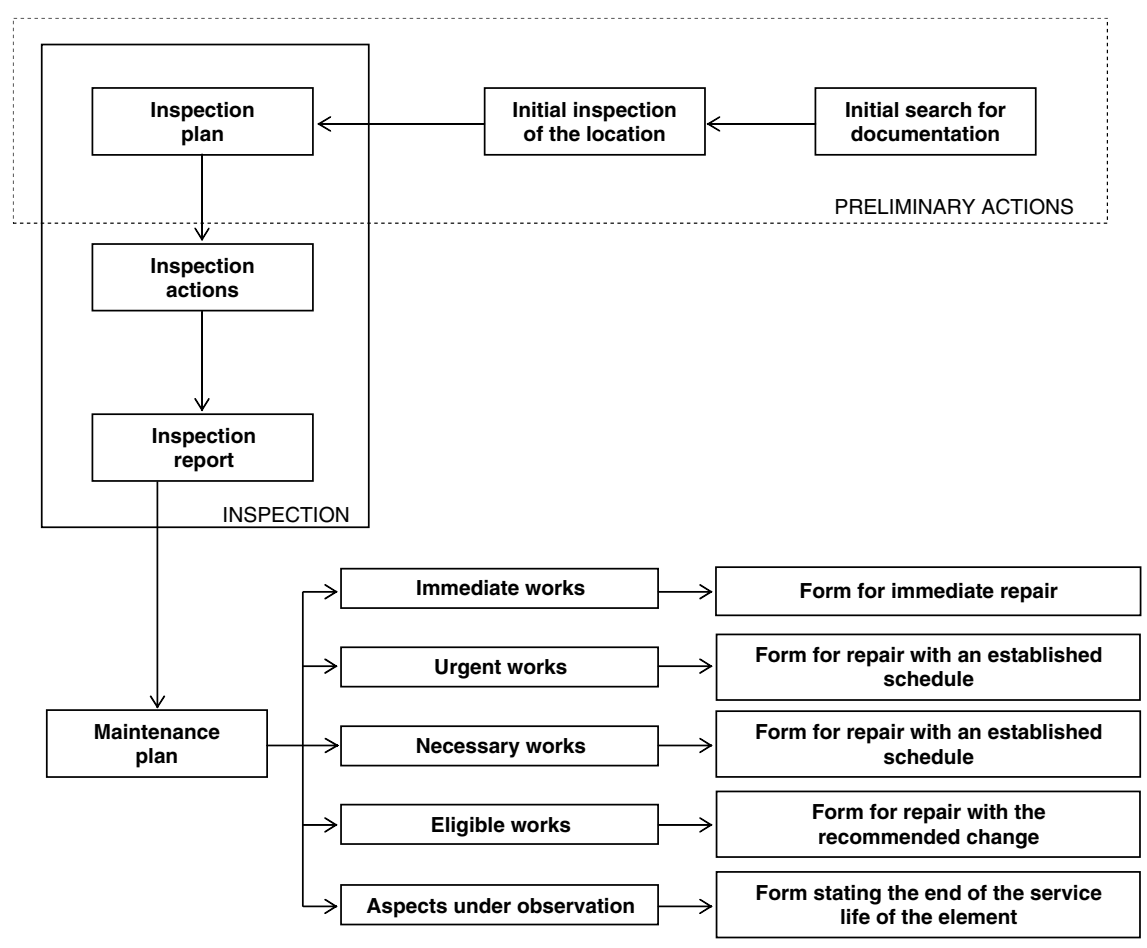

Figure 6: Sequence of actions during an inspection

As for the structure of the document, Feilden (2003) presents an action ranking, to be considered in the preparation of maintenance plans (Figure 6):

(a) Immediate works: Actions aimed at guaranteeing the users/building's structural safety.

(b) Urgent works: Actions aimed at preventing course deterioration, such as xylophagous attack, water entrance or imminent fall of ornaments.

(c) Necessary works: Actions aimed at adjusting the building to its present or envisioned use; preventive maintenance must be dealt with.

(d) Eligible works: Actions aimed at emphasising the elements looks and at improving/ adapting the building's use; in the case of gypsum plasterwork, these actions are particularly important.

(e) Aspects to be kept under observation: Identification of the aspects capable of causing future damage, such as active structural movements, roofing conditions, and technical installations, or networks near the end of their service live.

At the end of the stage of analysis, compilation, and establishment of action proposals, rehabilitation work enters a new stage of consolidation of strategies and of definition of the elements to intervene. The preparation of the restoration project thus begins.

\section{PREPARATION OF THE RESTORATION PROJECT}

The restoration project is a fundamental document, recommended by the Krakow Chart 2000 (2000), in which the critical choice decisions are materialised and the rules for intervention on degraded gypsum plasterwork are established. The project is based on 
appropriate technical options, resulting from the research process, the analysis of data and consequent knowledge of the building at various levels: structural, constructive, graphic, volumetric, historical, artistic, and socio-cultural.

As for the project of other technical areas, in the restoration project the data needed for the execution of the works are registered, for example, appraisal of the situation, demands to observe during the execution, calculations, and other information essential to rehabilitation. Its preparation must be coordinated by an expert in the area of construction, with knowledge of conservation and restoration and on the execution and coordination of rehabilitation project. Frequently, it is an Architect due to the need of articulating the different technical areas involved in rehabilitation.

This project must also identify anomalies in other elements that, prior to the gypsum plasterwork treatment, reveal the need of a preliminary intervention, and contemplate the following aspects:

- degraded construction elements that indirectly affect the plastered elements;

- sequence of interventions in the various construction elements;

- objectives of each intervention.

The analysis of options, in terms of choice of materials and solutions, implies that in the restoration project the one considered most adequate is identified, within the principles of heritage conservation. The possibility of preparing alternative proposals must be foreseen, however, for later appreciation. The restoration project coordinator must also be aware of the need of establishing time frames for action in each stage of the works and the respective budgets, not leaving them to be randomly adopted according to the needs of the contractor responsible for the rehabilitation.

The restoration project must be composed by a set of written and drawn parts, with precise description of the works to be done, adapted from what composes a current construction project, namely:

- a descriptive and justificatory memory of the solutions and techniques adopted;

- data on the situation appraisal and eventual maintenance plan;

- drawings of the global situation (plans, cross-sections and elevations, at 1:50 or 1:100 scale) (Figure 7) and of detailing (at a scale 1:1 to 1:20);

- calculations;

- technical clauses;

- estimated budget.

A preliminary definition of the long-term conservation strategy of the various elements subjected to rehabilitation may also be included in the project.

\section{DECISIONS MADE ON SITE}

Making decisions at the same time as the works are executed may be an indispensable procedure no matter how detailed the appraisal, the results obtained from the inspection and the restoration project. So, any rehabilitation action must start with the confirmation of all these data at the intervention site. In this sense in loco decision becomes necessary at any moment of the rehabilitation works eventually forcing the adaptation of the established intervention plan. This aspect is particularly important for hidden areas, only visible during the works, where the confirmation of data is done only during the preparation for execution, such as anomalies in the 

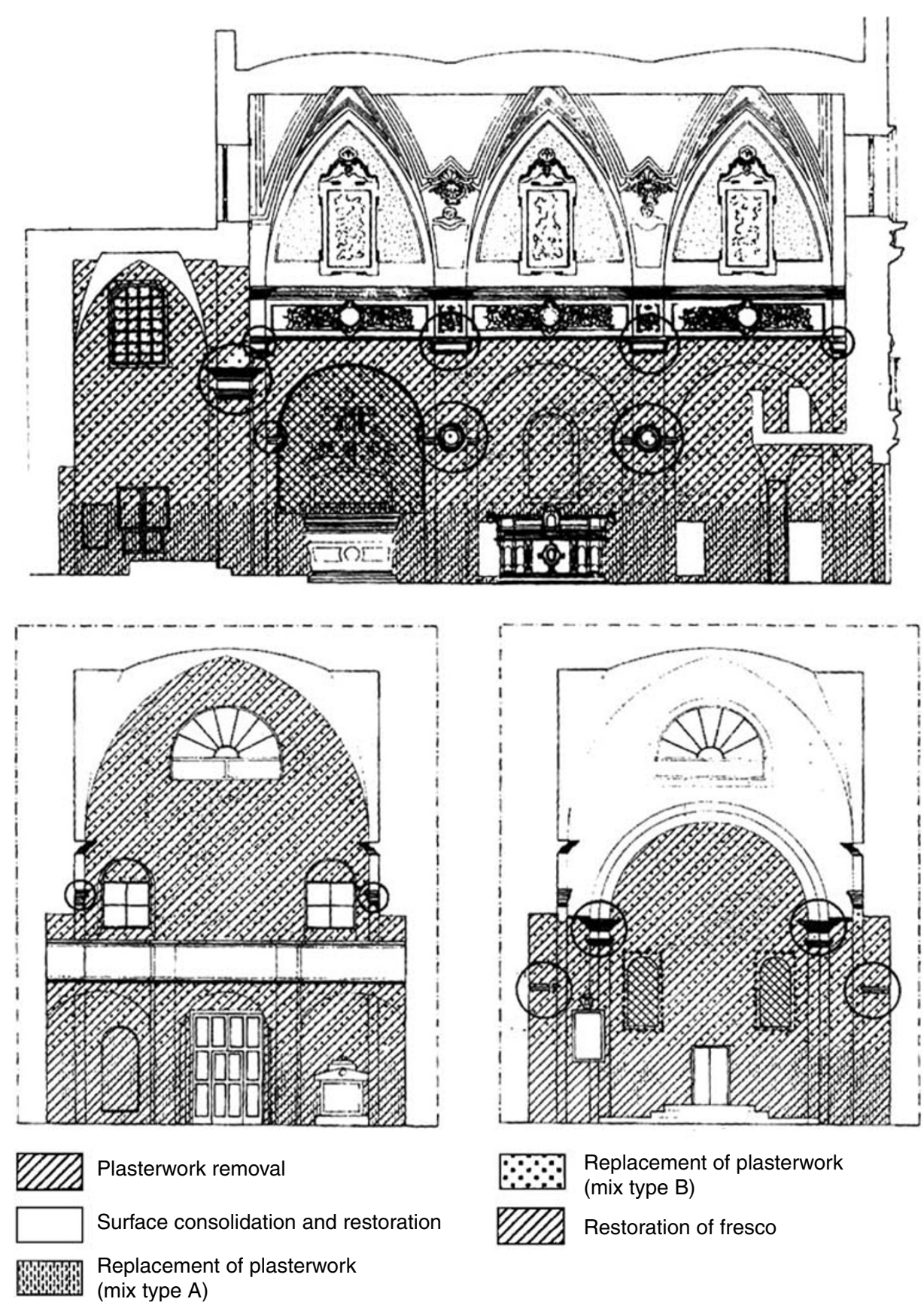
$\because \because \therefore \begin{aligned} & \text { Replacement of plasterwork } \\ & \text { (mix type B) }\end{aligned}$

Restoration of fresco

Figure 7: Interior elevations of a church, an example of register of interventions to be made in different areas

background or when the removal and consolidation of the plasterwork is determined, before any other work.

\section{Evaluation of the real situation}

Rehabilitation actions are performed at a level of certainty that in principle precludes changes from the frame of intervention defined in project. When the analysis of the real conditions does not, however, confirm the presuppositions, it forces adoption of a 


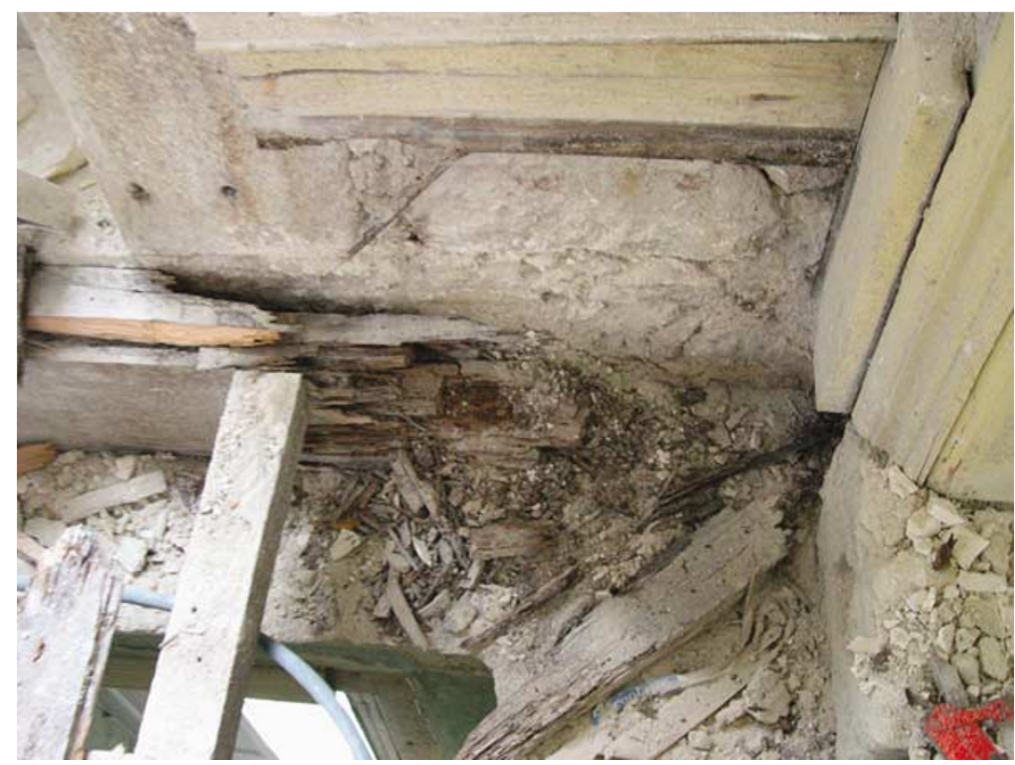

Figure 8: Rot of timber beam next to outer wall, visible only after the pavement was dismantled (Morais Villa in Ponte de Lima, Portugal)

new logic of intervention or a new stage planning of the works. Then a revaluation is needed of the execution of a certain intervention, the sequence of works, and the definition of the materials/solutions more adequate to the physical properties of the gypsum plasterwork, even with the practical application of the solution prescribed in project.

The importance of this diagnosis is evident in the rehabilitation of the gypsum plasterwork of the Church of Cowdray House, where Ashurst and Ashurst (1988) describe different options decided only within the real context of the action. In this situation, even though knowing beforehand the anomalies and the way to correct them, the restoration teams executed the works with no absolute certainty concerning the action to implement and, as the work proceeded and after the identification of the real conditions of the elements, the modus faciendi was constantly the object of analysis. This example proves how the permanent evaluation of the results can affect the rehabilitation works due to the identification of new anomalies, the extension of the ones already identified or the arising of unexpected behaviours during the works.

Floors are generally made of timber, in which the damage found in most cases is due to bad conservation of the support due to water entrance (Cotrim et al., 2006). This anomaly can only be clearly identified after dismantling the coverings and right before the execution of the rehabilitation works (Figures 8 and 9), however, corroborating the need for an exhaustive inspection, namely at the level of the roofs beams system, in order to determine the elements to be replaced or treated on site .

\section{Observation, preparation, and stabilisation}

As stated previously, rehabilitation works must be performed in the sequence of implementation and articulation of three preliminary operations: observation, preparation, and stabilisation. The summation of these operations concurs to the confirmation and 
装: Cotrim, Veiga and Brito

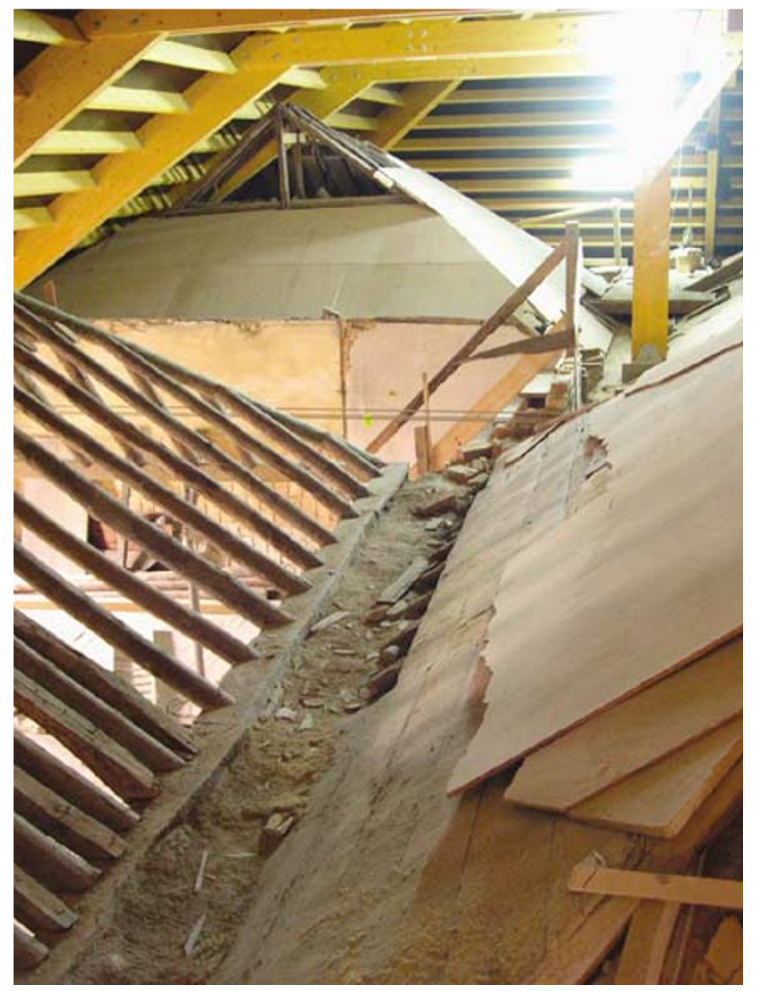

Figure 9: Extrados of plastered roofs: original structure and new support of the roofs (Marquis of Pombal Palace in Lisbon)

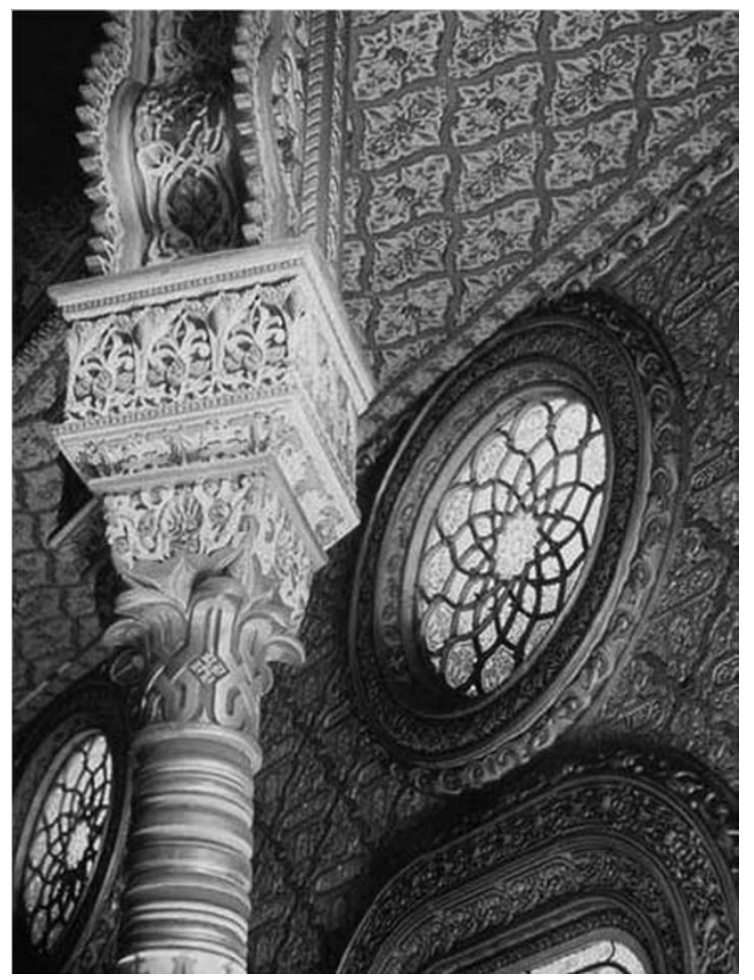

Figure 10: Stock Exchange in Porto 
validation of the execution mode of the rehabilitation actions, in accordance with a certain context and in the face of real acting conditions. It can be concluded that the lack of knowledge of the acting conditions certainly leads the way to a poorly performed work. Any task must be performed in perfect safety conditions, with as much as possible unexpected situations under control and within an objective frame of intervention. It is thus essential to observe the elements whose conservation conditions cannot be appraised at the stage of appraisal and inspection.

The sequence of implementation of these operations is not single; neither can it be established beforehand. Only as a function of the characterisation of the damages, their extension and the locations affected can the rehabilitation works follow a coherent flux according to an acting context.

Access to hidden areas may also reveal anomalies or constructive situations not identified by the inspection, such as poor stability conditions that for safety reasons lead to the need for provisional structures for circulation over the roof.

In conclusion, it is stressed that this methodology for the execution of rehabilitation of ancient gypsum plasterwork (Figure 10) does not follow a simple plan. Nevertheless, it is concluded that all preliminary actions destined to identify and characterise exhaustively the anomalies contribute decisively to the execution of an objective and rational work, allowing its inclusion in a restoration project capable of controlling almost every situation and therefore also its costs.

\section{Acknowledgments}

We acknowledge the support of the ICIST Research Institute from IST, Technical University of Lisbon.

\section{References}

Alessandrini, G., Bonecchi, R., Bugini, R., Fedeli, E., Ponticelli, S., Rossi, G. and Toniolo Bramante, L. (1989) 'Milan: the cascina pozzobonelli', Technical Examination and Restoration, Studies in Conservation, 34(2), 53-66.

Ashurst, J. and Ashurst, N. (1988) Practical Building Conservation. English Heritage Technical Handbook: Volume 3: Mortars, Plasters and Renders, Ashgate, Aldershot, UK.

Bankart, G. (2002) The Art of the Plasterer, Donhead Publishing Ltd, UK.

Binda, L., Saisi, A. and Tiraboschi, C. (2000) 'Investigation procedures for the diagnosis of historic masonries', Construction and Building Materials, 14, 199-233.

Callieri, M., Cignoni, P., Scopigno, R., Gori, G. and Risaliti, M. (2006) 'Beyond manual drafting: a restoration-oriented system', Journal of Cultural Heritage, 7(3), 214-226.

Cotrim, H. (2004) 'Ancient Gypsum Plasters Rehabilitation', Masters Thesis in Construction, IST, Technical University of Lisbon, Lisbon, p. 218 (in Portuguese).

Cotrim, H., Veiga, M.R. and de Brito, J. (2006) 'Freixo palace: rehabilitation of decorative gypsum plasters', Construction and Buildings Materials, doi:10.1016/f.conbuildmat.2006.05.080.

Cramer, J. (1986) Topographic appraisal in construction: measuring and reconnaissance Castellana (ed.), Editorial Gustavo Gili, Barcelona (in Spanish).

Eckel, E.C. (2005) Cements, Limes and Plasters. 3rd edn. rev. (1st edition: 1928), Donhead Publishing Ltd, UK.

Faria, J.A. (2002) 'Rehabilitation of timber structures in historical buildings', Estudos/Património, 3, 8-13 (in Portuguese).

Feilden, B.M. (2003) Conservation of Historic Buildings, 3rd edn. rev. (1st edition: 1982), Architectural Press, London.

Gárate Rojas, I. (1999) The Art of Gypsum: Quarries and Plasters, Spanish Institute of Architecture, Editorial MunillaLeria, Madrid (in Spanish).

Gleeson, J.F. (2002) 'The survey and inspection of external plasterwork for repair and replacement', http://www. plasterarc.net/essay/essay/Gleeindex.html, University of Reading, UK, Accessed 1st December, 2003.

Henriques, F. (2001) 'Dampness in walls', National Laboratory of Civil Engineering (LNEC), Lisbon (in Portuguese). 
Hodgson, F.T. (1901) Plaster and Plastering: Mortars and Cements, How to Make and How to Use, The Industrial Publication Company, New York, 70pp.

Isik, B. (2001) Experimental Study with the Gypsum Stabilized Earthen Wall Material: Alker, for Sustainable Habitat, Science Conference 2001, Yemeni Scientific Research Foundation, Sana'a.

Krakow Chart 2000 (2000) 'Principles for the conservation and restoration of built heritage', 4pp.

Leeke, J. (1985a) 'Problems with plaster, part one', Part One, Landmarks Observer, 12, 10-14.

Leeke, J. (1985b) 'Problems with plaster, part two', Part Two, Landmarks Observer, 12, 12.

Leeke, J. (1987) 'Saving irreplaceable plaster', Old House Journal, 15(6), 51-55.

Magalhães, A., Matias, L., Vilhena, A., Veiga, M.R. and Santos, P. (2005) 'Non-destructive testing for the assessment of moisture defects on ancient walls. Some case studies', Eighth International Conference on Non-destructive Investigations and Microanalysis for the Diagnosis and Conservation of the Cultural and Environmental Heritage, Lecce, Italy.

Mateus, J.M. (2002) Traditional Construction Techniques of Masonries: The Technical Literature from 1750 to 1900 and its Contribute to the Conservation of Historical Buildings, Horizon Books, Lisbon (in Portuguese).

Meira, A. (1999) 'Afife. Land of Plasterers', Oflito Lithography, Viana do Castelo, 15-17 (in Portuguese).

Millar, W. (1998) Plastering Plain and Decorative, Donhead Publishing Ltd, UK.

Poore, P. (1988) 'The basics of plaster repair', Old House Journal, 16(2), 29-35.

Ribeiro, P.S. (2000) 'Ancient gypsum plasterwork: constructive characterization and pathological analysis', Masters Thesis in Construction, IST, Technical University of Lisbon, Lisbon, 177pp. (in Portuguese).

Ribeiro, P.S., Veiga, M.R. and de Brito, J. (2007) 'Gypsum coatings in ancient buildings', Construction and Buildings Materials, 21(1), 126-131.

Santos, C., Matias, L., Magalhães, A. and Veiga, M.R. (2003) 'Application of thermography and ultra-sounds for wall anomalies diagnosis', International Symposium Non-Destructive Testing in Civil Engineering (NDT-CE), Berlin, Germany.

Sawyer, J.T. (2007) Plastering, Donhead Publishing Ltd, UK.

Shivers, N. (1989) Walls and Molding: How to Care for Old and Historic Wood and Plaster, National Trust for Historic Preservation, Washington, DC.

Silva, P.A., Prata, P., Joaquim, A. and Rana, M. (2001) 'Interventions of DGEMN at the Bishop's palace of Porto', Monumentos, 14, 82-91 (in Portuguese).

Vadstrup, S. (2001) 'Working techniques and repair methods for plaster decorations on facades', Centre for Restoration and Traditional Crafts, Denmark, www.plasterarc.net/essay/essay/Sorenindex.html, Accessed 26th March, 2007.

Vasconcelos, F. (1991) 'Gypsum plaster, the Baroque privileged decoration', First Baroque International Congress, Porto, Portugal (in Portuguese).

Vasconcelos, F. (1997) The Gypsum Plasterwork of Porto, Collection Porto Patrimony, Porto Municipal County, Portugal (in Portuguese).

Veiga, M.R., Aguiar, J., Silva, A.S. and Carvalho, F. (2001) 'Methodologies for characterisation and repair of mortars of ancient buildings', International Seminar Historical Constructions 2001, Guimarães, Portugal. 